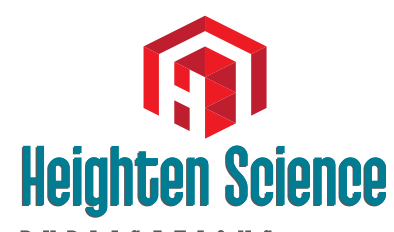

P U B L I C I T I O N S Corporation
*Address for Correspondence: Akanksha Rathi, Assistant Professor, Department of Community Medicine, Dr. Baba Saheb Ambedkar Medical

College \& Hospital, New Delhi, India,

Email: akanksharathi.dr@gmail.com

Submitted: 10 January 2018

Approved: 18 January 2018

Published: 19 January 2018

Copyright: ๑ 2018 Rathi A. This is an open access article distributed under the Creative Commons Attribution License, which permits unrestricted use, distribution, and reproduction in any medium, provided the original work is properly cited

Check for updates
Letter to Editor

\section{Importance of prevention-A letter to the editor}

\author{
Akanksha Rathi* \\ Assistant Professor, Department of Community Medicine, Dr. Baba Saheb Ambedkar Medical \\ College \& Hospital, New Delhi, India
}

In today's busy world, people don't even have the time to fall ill. Diseases don't just demand time but also physical efforts, mental peace, loss of work, distress of loved ones and financial loss. According to a report published in Harvard business review, each year in India, 39 million people are pushed into poverty by out-of-pocket payments for healthcare, with households on average devoting $5.8 \%$ of their expenditures to medical care [1].

Over $50 \%$ of all deaths are because of chronic diseases, that we call lifestyle diseases. It means, $50 \%$ of the deaths can be prevented by lifestyle modifications. Even $40 \%$ of cancer, the disease which is the dreaded the most, can be prevented through healthy lifestyle. According to the World Health Organization (2005), the estimated loss in India's national income due to heart diseases, stroke and diabetes in 2005 was US $\$ 9$ billion. These losses are projected to exceed US $\$ 200$ billion in the next decade, unless preventive measures are taken in which case, an accumulated economic growth of US $\$ 15$ billion can be expected [2].

Such is the power of prevention. People need to be made aware of the risk factors and healthy lifestyles and it can remove a big burden from the healthcare system of the country. On an individual level too, it will help a great deal as people will be empowered to lead a healthy life.

It's high time we give preventive health care its log due respect and make this world a healthier and happier place.

As the saying goes "prevention is better than cure...", but such is the wrath of chronic diseases that the saying should be rephrased into "prevention is better than NO cure at all".

\section{References}

1. Ref.: http://www.aravind.org/aravindcontentmanagement/file/MF00000053.pdf

2. Impact of preventive health care on Indian industry and economy. Ref.: https://goo.gl/3ZYMo2 